\title{
The long-term performance of Hong Kong share-only and unit initial public offerings (IPOs)
}

\author{
Khelifa Mazouz $^{\mathrm{a}}$, Brahim Saadouni ${ }^{\mathrm{b}}$, Shuxing Yin ${ }^{\mathrm{c}, *}$ \\ a Aston Business School, Aston University, Birmingham, UK \\ ${ }^{\mathrm{b}}$ Manchester Business School, The University of Manchester, Manchester, UK \\ ${ }^{\mathrm{c}}$ The Business School, University of Hertfordshire, Hertfordshire, UK \\ Received 26 January 2007; accepted 16 August 2007 \\ Available online 25 August 2007
}

\begin{abstract}
This study examines the long-term price performance of share-only versus unit IPOs issued on the Hong Kong Stock Exchange during 1990-2002. Our main objective is to test the extent to which the agency cost and signaling models explain the reasons for unit IPOs issuance using the long-term price performance approach. The agency cost model suggests that firms include warrants in their offerings to bind managers to optimal investment decisions. Under this model, unit IPOs are expected to possess better quality projects and, therefore, generate higher long-term risk-adjusted returns than share-only IPOs. The signaling model expects unit IPOs to be riskier than share-only IPOs. To compensate investors for bearing the extra risk, unit IPOs should yield higher returns than share-only IPOs in the long run. Thus, the signaling model expects unit IPOs to outperform share-only IPOs at least before conducting appropriate risk adjustments. Our long-term price performance evidence rejects the predictions of both models.
\end{abstract}

(C) 2007 Elsevier B.V. All rights reserved.

JEL classification: G14; G30

Keywords: Unit IPOs; Share-only IPOs; Long-term abnormal returns

\section{Introduction}

A unit IPOs is a bundle of warrants with equity in an initial public offering (IPOs). Its holders have the right to uncertain gains either by selling or exercising their warrants, if the stock price

\footnotetext{
* Corresponding author. Tel.: +44 1707281242; fax: +44 1707285455 .

E-mail addresses: k.mazouz@aston.ac.uk (K. Mazouz), b.saadouni@manchester.ac.uk (B. Saadouni), s.yin@herts.ac.uk (S. Yin).
} 
rises above the exercise price. Practitioners often regard the warrants in the unit IPOs package as "sweeteners" used to boost weak demand for low quality offerings. Academics argue that the practitioners' view is unsatisfactory. Schultz (1993) argues that the unit financing arrangements can be explained by the agency cost model. Using the US data, he shows that unit IPOs are used to lower agency costs by reducing the probability of the excess cash being invested in low quality projects. Chemmanur and Fulghieri (1997) propose a signaling model that focuses on the interaction of asymmetric information and managers' risk aversion as a possible explanation of the unit issuance. The signaling model suggests that unit issuers are relatively riskier than shareonly issuers and warrants are included in the offering to reveal the managers' expectations about the future prospects of the firm's cash flows. How and Howe (2001) and Lee et al. (2003) provide Australian evidence in favour of the signaling hypothesis.

Previous studies ${ }^{1}$ focus on the characteristics and initial returns of share-only and unit IPOs to test the implications of the agency cost and signaling models. The main contribution of this study stems from the use of the long-term price performance approach to test the agency cost and the signaling explanations of unit IPOs issuance. To date, there is no study that carefully compares the long-term performance of share-only IPOs with that of unit IPOs. ${ }^{2}$ This study fills this gap by examining the long-term performance of share-only IPOs and unit IPOs issued on the Hong Kong Stock Exchange (HKSE) between January 1990 and December 2002.

The agency cost model of Schultz (1993) suggests that the inclusion of warrants in unit offerings bind managers to optimal investment decisions, as investors are unlikely to exercise their warrants when the investment opportunities are uneconomical. Thus, the agency cost model expects unit issuers to possess better quality projects and, therefore, generate significantly higher risk-adjusted abnormal returns than share-only IPOs in the long run. Chemmanur and Fulghieri's (1997) suggest that units are a feasible financing means for high-risk firms. If units are issued by high-risk firms, one would expect unit IPOs to generate higher yield in the long run than share-only IPOs in order to compensate for the higher risk undertaken by investors. In other words, the signaling model expects unit IPOs to outperform share-only IPOs in the long run at least before conducting appropriate risk adjustments. ${ }^{3}$

To provide a comprehensive comparison between unit and share-only IPOs in terms of their long-term price performance, this study uses a variety of methods for measuring long-term abnormal returns. The results from the event-time approach suggest that both unit and share-only IPOs underperform the market index. The observed underperformance shrinks greatly, and in most cases disappears, when unit and share-only IPOs returns are compared with the returns of non-IPOs firms matched on size, size-and-book-to-market ratio, and industry, size-and-book-tomarket ratio. However, the abnormal returns associated with unit IPOs are significantly lower than those of share-only IPOs and some other benchmarks of matched firms. Although the event-time approach may not adequately adjust for risk, this evidence can still be used against the signaling model. In other words, the signaling model expects unit IPOs to be riskier, and hence yield higher long-term returns than share-only IPOs at least before conducting appropriate risk adjustments. To mitigate the biases associated with the use of the event-time approach, we employ both standard

\footnotetext{
1 See, for example, Schultz (1993), How and Howe (2001) and Lee et al. (2003).

${ }^{2}$ Byoun (2004) is the only study that uses the long-term price performance approach to test the implications of the agency cost and the signaling models, but in the context of SEOs. He reports that in the long-term unit SEOs underperform both share-only SEOs and various benchmarks of matched firms.

3 According to the signaling model, the source of unit IPOs outperformance is their riskiness. Thus, the model does not expect unit IPOs to yield higher returns than share-only IPOs after appropriately adjusting for risk.
} 
Table 1

Distribution of the sample, 1990-2002

\begin{tabular}{lcrr}
\hline Year & Share-only IPOs & Unit IPOs & All IPOs \\
\hline 1990 & 7 & 6 & 13 \\
1991 & 24 & 24 & 48 \\
1992 & 19 & 35 & 54 \\
1993 & 32 & 29 & 61 \\
1994 & 33 & 16 & 49 \\
1995 & 20 & 4 & 24 \\
1996 & 38 & 6 & 44 \\
1997 & 65 & 11 & 76 \\
1998 & 28 & 1 & 29 \\
1999 & 27 & 1 & 28 \\
2000 & 37 & 0 & 37 \\
2001 & 29 & 1 & 30 \\
2002 & 41 & 3 & 44 \\
$1990-2002$ & 400 & 137 & 537 \\
\hline
\end{tabular}

The table lists the number of firms that went public on the HKSE during 1990-2002 by the issue year and issue type.

calendar-time and matched calendar-time regressions. The standard calendar-time factor regression suggests significantly negative abnormal returns exist for both share-only and unit IPOs only when the equally weighted returns are used. Since our IPOs sample is tilted towards small and high growth firms, the observed negative abnormal return is likely due to the fact that standard calendar-time factor regression overrejects the null hypothesis of zero intercept (see, for example, Fama, 1998; Mitchell and Stafford, 2000). To better control for firm size-and-book-to-market characteristics, we use matched calendar-time factor regression. ${ }^{4}$ Regardless of whether equally or value-weighted returns are used, the intercepts of the matched calendar-time factor regressions associated with share-only IPOs and unit IPOs are not significantly different from zero. Viewed collectively, our results provide no support to the agency cost model, which expects unit IPOs to generate higher long-term risk-adjusted abnormal returns than share-only IPOs. Additionally, the evidence is also not consistent with the predictions of the signaling model, which expects unit IPOs to outperform share-only IPOs in the long run at least before conducting appropriate risk adjustments.

The rest of the paper is structured as follows. Section 2 contains a description of the sample of IPOs and the control samples. Section 3 outlines our empirical procedures and discusses our results. Section 4 concludes the paper.

\section{Data and descriptive statistics}

\subsection{The sample of IPOs}

We analyse a sample of 400 share-only IPOs and 137 unit IPOs listed on the HKSE from January 1990 to December 2002. Since we focus on the 3-year post-IPOs abnormal returns, our last data point is January 2006. Consistent with the prior literature, the close-end funds, investment trusts, and companies with missing data are excluded from the sample. The offering information

\footnotetext{
4 The matched calendar-time regression is used by Boehme and Sorescu (2002), Boehme and Danielson (in press), and Cheng (2005), among others.
} 
is obtained from both the Fact Book published by the HKSE and listed IPOs companies' prospectuses. Price, market value and book-to-market ratio data are obtained from Datastream. Table 1 presents the frequency distribution of all, share-only, and unit IPOs over the sample period. In the period from 1990 to 1993, the sample is fairly balanced between share-only IPOs (82 firms) and unit IPOs (94 firms). The proportion of unit IPOs relative to the total number of IPOs has decreased sharply since $1994 .^{5,6}$

Table 2 summarizes the size-and-book-to-market rankings of the IPOs firms as of the listing month, as well as their industry distribution. In the size ranking, at the beginning of each month, ${ }^{7}$ we rank HKSE firms by their market value of equity, which is calculated as the number of shares outstanding multiplied by the share price, placing them into deciles. Similarly, in book-to-market ranking, at the beginning of each month, we rank HKSE firms by the book-to-market ratio, which is computed as the book values from the most recent fiscal year after the IPOs divided by the market value of equity, placing them into deciles. ${ }^{8}$

Panels A and B of Table 2 list our sample firms by their size-and-book-to-market ratios, respectively. Overall, the HKSE IPOs tend to have small market value of equity and low bookto-market ratios. Panel A shows that half of the IPOs belong to the 4 smallest size deciles, and only less than $30 \%$ of the firms are in the 4 largest deciles. Panel B suggests that IPOs issuers are high growth firms with over $70 \%$ of the firms falling in the book-to-market deciles of 1-4 and only $9 \%$ in deciles of 7-10. Panels A and B of Table 2 also report size and market-to-book ratios of share-only and unit IPOs separately. Although share-only IPOs and unit IPOs are similar in terms of their growth opportunities, share-only IPOs tend to have larger market value of equity than unit IPOs. Specifically, only $45 \%$ of share-only IPOs are in the 4 smallest size deciles and $35 \%$ in the 4 largest size deciles. Conversely, most unit IPOs (64\%) belong to the 4 smallest size deciles and only $15 \%$ are in the 4 largest size deciles. The distribution of unit IPOs is consistent with the predictions of the agency cost and signaling models that unit IPOs are issued by smaller firms.

Panel C of Table 2 shows the industry distribution of our sample. Our data provides a clear indication of industry clustering in the Hong Kong IPOs market. For example, the manufacturing industry alone accounts for $43 \%$ of the total IPOs, followed by the finance, insurance and real estate industry with $14 \%$ and the wholesale trade industry with $13 \%$ of the total IPOs issued in our sample period. Both the agency cost and signaling models predict some degree of industry clustering for unit IPOs, since unit IPOs are issued when the future cash flows are relatively

\footnotetext{
5 The decline in the unit issues is not specific to the Hong Kong market. Byoun (2004), for example, examines the SEOs in the US market and shows that "... the proportion of unit issues relative to the total number of issues has been relatively low since 1995..." (p. 78).

6 The decline in the issuance of unit IPOs after 1994 coincides with the regulatory change in the HKSE listing requirements, which became effective from 15 September 1994. The objective of the new regulation is to screen out the poor IPOs performers. Our data reveals that over $90 \%$ of unit IPOs issued before 1994 pass the newly introduced regulatory requirements. Thus, the regulatory changes are unlikely to be the reason for the disappearance of unit IPOs in the recent years. Another possible explanation of the disappearance of unit IPOs is the increased popularity of derivative warrants in Hong Kong particularly post 1994 (see Table 1 in Chan and Wei, 2001). We claim that investors may have viewed derivative warrants as substitutes to the warrants in unit IPO packages. We choose to leave the empirical proof of this argument for the future research and focus in the rest of the paper on the long-term performance of share-only and unit IPOs.

7 We start from the first available monthly size and price observations in Datastream.

8 Aggarwal et al. (2006) argue that using book values from the most recent fiscal year after the IPOs accounts for the proceeds of the IPOs in the computation of the book-to-market ratio.
} 
Table 2

Size, book-to-market and industry distribution of the sample firms

\begin{tabular}{|c|c|c|c|c|c|c|}
\hline & \multicolumn{2}{|c|}{ Share-only IPOs } & \multicolumn{2}{|c|}{ Unit IPOs } & \multicolumn{2}{|l|}{ All IPOs } \\
\hline & Number & $(\%)$ & Number & $(\%)$ & Number & $(\%)$ \\
\hline \multicolumn{7}{|l|}{ Panel A: size } \\
\hline Decile 1-2 (smallest) & 48 & $(12.00 \%)$ & 32 & $(23.36 \%)$ & 80 & $(14.90 \%)$ \\
\hline Decile 3-4 & 130 & $(32.50 \%)$ & 56 & $(40.88 \%)$ & 186 & $(34.64 \%)$ \\
\hline Decile 5-6 & 85 & $(21.25 \%)$ & 28 & $(20.44 \%)$ & 113 & $(21.04 \%)$ \\
\hline Decile 7-10 (largest) & 137 & $(34.25 \%)$ & 21 & $(15.33 \%)$ & 158 & $(29.42 \%)$ \\
\hline \multicolumn{7}{|l|}{ Panel B: M/B } \\
\hline Decile 1-2 & 136 & $(34.00 \%)$ & 55 & $(40.15 \%)$ & 191 & $(35.57 \%)$ \\
\hline Decile 3-4 & 142 & $(35.50 \%)$ & 42 & $(30.66 \%)$ & 184 & $(34.26 \%)$ \\
\hline Decile 5-6 & 83 & $(20.75 \%)$ & 31 & $(22.63 \%)$ & 114 & $(21.23 \%)$ \\
\hline Decile 7-10 & 39 & $(9.75 \%)$ & 9 & $(6.57 \%)$ & 48 & $(8.94 \%)$ \\
\hline \multicolumn{7}{|l|}{ Panel C: industry (SIC code) } \\
\hline Manufacturing (2000-3999) & 171 & $(42.75 \%)$ & 62 & $(45.26 \%)$ & 233 & $(43.39 \%)$ \\
\hline $\begin{array}{l}\text { Finance, insurance and real estate } \\
(6000-6799)\end{array}$ & 52 & $(13.00 \%)$ & 20 & $(14.60 \%)$ & 72 & $(13.41 \%)$ \\
\hline Wholesale trade (5000-5199) & 45 & $(11.25 \%)$ & 24 & $(17.52 \%)$ & 69 & $(12.85 \%)$ \\
\hline $\begin{array}{l}\text { Transportation, communications, electric, } \\
\text { gas and sanitary services (4000-4999) }\end{array}$ & 51 & $(12.75 \%)$ & 11 & $(8.03 \%)$ & 62 & $(11.55 \%)$ \\
\hline Services $(7000-8999)$ & 33 & $(8.25 \%)$ & 9 & $(6.57 \%)$ & 42 & $(7.82 \%)$ \\
\hline Retail trade (5200-5999) & 27 & $(6.75 \%)$ & 4 & $(2.92 \%)$ & 31 & $(5.77 \%)$ \\
\hline Construction (1500-1799) & 13 & $(3.25 \%)$ & 7 & $(5.11 \%)$ & 20 & $(3.72 \%)$ \\
\hline Mining (1000-1499) & 4 & $(1.00 \%)$ & 0 & $(0.00 \%)$ & 4 & $(0.74 \%)$ \\
\hline $\begin{array}{l}\text { Agriculture, forestry, fishing, hunting and } \\
\text { trapping (0100-0999) }\end{array}$ & 3 & $(0.75 \%)$ & 0 & $(0.00 \%)$ & 3 & $(0.56 \%)$ \\
\hline Public administration (9100-9999) & 1 & $(0.25 \%)$ & 0 & $(0.00 \%)$ & 1 & $(0.19 \%)$ \\
\hline
\end{tabular}

This table describes the size, book-to-market and industry distribution of the sample firms. In the size ranking, for each month, we rank HKSE firms by their market value of equity, which is calculated as the number of shares outstanding multiplied by the share price, at the beginning of the month, placing them into deciles. Similarly, in book-to-market ranking, for each month, we rank HKSE stocks by their book-to-market ratio, which is computed as the book values from the most recent fiscal year after the IPOs divided by the market value of equity, placing them into deciles. Each IPOs firm is assigned to one industry using primary SIC codes.

uncertain and the viability of investment opportunities may vary systematically across industries. However, Panel $\mathrm{C}$ of Table 2 shows that the observed industry clustering does not depend on whether the new issue is a share-only or a unit IPOs. ${ }^{9}$

\subsection{The control samples}

To provide some links to previous studies, particularly Ritter (1991), Loughran and Ritter (1995), Eckbo and Norli (2005) and Álvarez and González (2005), we systematically compare the returns on IPOs to a set of control firms matched by size, size-and-book-to-market ratio, and industry-size-and-book-to-market ratio. Size matched firms are selected from the list of all HKSE companies at the end of the year prior to the IPOs. The size-matched firm is the non-IPOs

\footnotetext{
${ }^{9}$ We account for this industry clustering by including industry as one of the selection criteria in our control sample methodology (see Section 2.2).
} 
firm closest in market value of equity to the IPOs firm. When matching is based on size and the book-to-market ratio, we select the subset of non-IPOs firms with market value of equity within $30 \%$ of the IPOs firm's market capitalization. We then rank the selected subset on their book-to-market ratios and define the size-and-book-to-market matched firm as the non-IPOs firm with the book-to-market ratio that is closest to the IPOs firm's book-to-market ratio. Finally, in industry-size-and-market-to-book ratio matching, the matched firms are selected in the same way as size-and-book-to-market matching with the restriction that the non-IPOs firm belongs to the same industry as the IPOs firm. ${ }^{10,11}$

Table 3 shows the size-and-book-to-market ratios of the IPOs firms and their matched pairs. Regardless of the IPOs type or the matching procedures, the size of IPOs is not significantly different from the size of their matched firms whereas the book-to-market ratio of the IPOs stocks is significantly lower than that of the control sample. The difference in book-to-market ratios between IPOs and their matched firms calls for the use other methods to better account for firms' characteristics when measuring the long-term performance.

\section{Tests and results}

\subsection{Event-time abnormal returns}

The issue as to whether cumulative abnormal return (CAR) or buy-and-hold abnormal returns (BHAR) should be used to measure the long-term price performance is widely debated in the literature. For robustness purposes, we report both the CAR and BHAR in this study.

We monitor our samples of all, share-only and unit IPOs for a period of 3 years subsequent to their issuance. Following Cheng (2005), we use both event-induced average cumulative abnormal return $(\overline{\mathrm{CAR}})$ and event-induced average buy-and-hold abnormal return $(\overline{\mathrm{BHAR}})$ to measure the abnormal returns associated with our sample of IPO firms. The 3-year $\overline{\mathrm{CAR}}$ and $\overline{\mathrm{BHAR}}$ are computed as follows

$$
\begin{aligned}
& \overline{\mathrm{CAR}}=\sum_{i=1}^{N} w_{i} \mathrm{CAR}_{i} \\
& \overline{\mathrm{BHAR}}=\sum_{i=1}^{N} w_{i} \mathrm{BHAR}_{i}
\end{aligned}
$$

where $w_{i}$ is the weight on firm $i$ and $N$ is the number of firms. The 3 -year $\overline{\mathrm{CAR}}$ and $\overline{\mathrm{BHAR}}$ are calculated using both equally and value-weighted returns. The value weights are based on the market value of equity at the end of the event month. The firm $i$ 's event-induced cumulative abnormal return $\left(\mathrm{CAR}_{i}\right)$ and event-induced buy-and-hold return $\left(\mathrm{BHAR}_{i}\right)$ are estimated as

$$
\mathrm{CAR}_{i}=\sum_{t=1}^{36} R_{i, t}-R_{\mathrm{B}, t}
$$

\footnotetext{
${ }^{10}$ For all the matchings, if a matching firm is delisted before the 3-year holding period elapses, a new match is drawn from the original list of candidates.

${ }^{11}$ For all the matchings, an IPOs firm is included our analysis for the full 3-year study period or until they are delisted, whichever earlier.
} 
Table 3

Size-and-book-to-market characteristics of the IPOs firms and their non-issuing control firms matched on size, size-and-book-to-market ratio, and industry-size-and-book-tomarket ratio

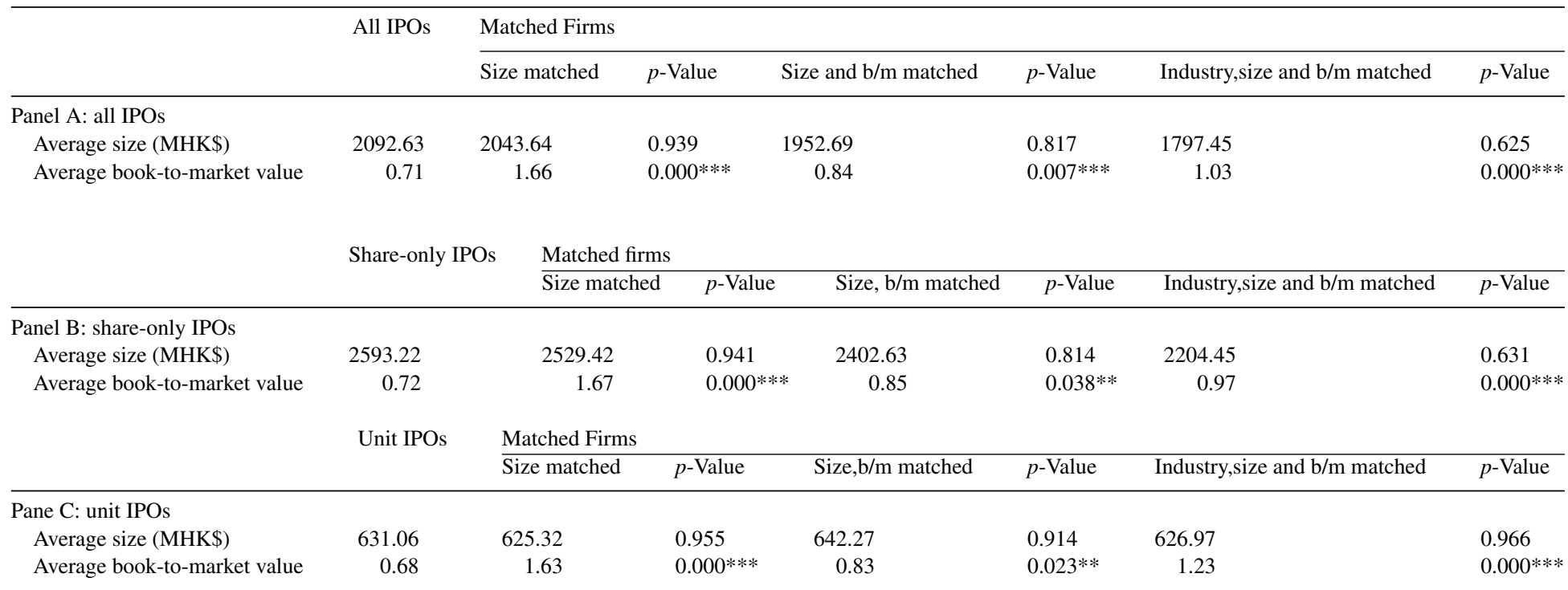

This table describes the size-and-book-to-market characteristics of the 537 firms that went public on the HKSE between 1990 and 2002 and their non-issuing control firms matched on size, size-and-book-to-market ratio, and industry-size-and-book-to-market ratio. Size matched firms are selected from the list of all HKSE companies at the end of the year prior to the IPOs, which are not in our sample of IPOs for a period of 3 years prior to the offer date. The size-matched firm is the non-IPOs firm closest in market value of equity to the IPOs firm. When matching is based on size-and-book-to-market ratio, we select from the list HKSE companies, the subset of non-IPO firms with market value of equity within $30 \%$ of the IPOs firm's market capitalization. We rank the selected subset on their book-to-market ratios and define the size-and-book-to-market matched firm as the non-IPOs firm with the book-to-market ratio that is closest to the IPOs firm's ratio. Finally, in industry-size-and-market-to-book ratio matching, the matched firms are selected in the same way as size-and-book-to-market matching with the restriction that the non-IPOs firm belongs to the same industry as the IPOs firm.

$* * *$ and $* *$ indicate significance at $1 \%$ and $5 \%$ levels, respectively. 


$$
\mathrm{BHAR}_{i}=\prod_{t=1}^{36}\left(1+R_{i, t}\right)-\prod_{t=1}^{36}\left(1+R_{B, t}\right)
$$

where $R_{i, t}$ is the monthly return of an event firm $i$ in month $t$ and $R_{\mathrm{B}, t}$ is the monthly return of benchmark firm or portfolio. For robustness purposes, we measure the long-term performance of the event firms with respect to various benchmarks, including a value-weighted market index (Hang Seng index) and a non-event firm matched with the event firm on size, size-andbook-to-market ratio, and industry-size-and-book-to-market ratio. ${ }^{12}$ To determine the statistical significance of $\overline{\mathrm{CAR}}$ and $\overline{\mathrm{BHAR}}$, we employ the adjusted $t$-statistic by Brown and Warner (1980) and the skewness-adjusted $t$-statistic by Lyon et al. (1999), respectively.

Table 4 shows the average CARs generated from using the market index and matched firms as reference portfolios. Panel A of Table 4 suggests that the equally weighted average CARs depend largely on the type of IPOs and choice of benchmarks. For example, when the market index is the benchmark, the equally weighted average CARs associated with the samples of all, shareonly, and unit IPOs are significantly negative, at $-74.83 \%,-67.84 \%$ and $-95.22 \%$, respectively. However, a large part of the observed underperformance disappears when matched firms are used as reference portfolios. Specifically, by using control firms matched by size, the equally weighted average CARs generated by the three samples decrease to $-17.78 \%,-12.80 \%$ and $-32.33 \%$, respectively. These values shrink even further when industry is included in the matching process. When size-and-book-to-market ratio or industry-size-and-book-to-market ratio is used for matching purposes, the underperformance of all and share-only IPOs disappears completely, whereas the sample of unit IPOs significantly underperform its benchmarks by about $28 \%$.

Panel B of Table 4 presents the 3-year value-weighted average CARs associated with different IPOs samples under various benchmarks. The samples of all, share-only and unit IPOs still underperform the market index. However, the negative abnormal returns observed for the valueweighted average CARs are lower in magnitude than those generated by the equally weighted average CAR, suggesting that the equally weighted average CAR is driven by small-firm stocks. The value-weighted average CARs suggest that the performance of the samples of all and shareonly IPOs is not significantly different from that of their matched firms. Similar to the case of the equally weighted average CARs and regardless of benchmarks, the value-weighted average CARs approach provides evidence of unit IPOs underperformance.

Panel C of Table 4 provides a direct comparison of the long-term price performance between share-only and unit IPOs over 1990-1997 period. ${ }^{13}$ The non-parametric Mann-Whitney test suggests that, regardless of the methodologies used to estimate the CARs, unit IPOs perform

\footnotetext{
12 Barber and Lyon (1997) show that the control sample approach yields a well-specified test statistic. Specifically, they show that the control sample approach eliminates a number of biases, including rebalancing bias and skewness bias, associated with measuring the long-term abnormal returns. Although the Hong Kong market is relatively small, we still find a reasonably good non-IPOs match for each IPOs firm. This is particularly the case when the matching is based only on firm size. As shown in Table 3, unit IPOs and share-only IPOs are not significantly different from their matched firms in terms of size. Moreover, the fact that Hong Kong market is relatively small did not prevent us from finding good non-IPOs matched firms from the same industry as our IPOs firms. Finally, although IPOs firms differ from their non-IPOs matched firms in terms of the book-to-market ratio (see Table 3), the biases, if any, that may be caused by these differences are unlikely to persist when the matched calendar-time regression approach is employed (see Section 3.3 for more details).

13 Table 1 shows that only six unit IPOs are issued between 1998 and 2002. To avoid comparing the long-term price performance of unit IPOs issued over 1990-1997 period with share-only IPOs issued over 1990-2002, we only cover the 1990-1997 period for the direct comparison purposes.
} 
Three-year average cumulative abnormal return $(\overline{\mathrm{CAR}})$ for the sample firms

\begin{tabular}{|c|c|c|c|c|c|c|c|c|c|c|c|c|}
\hline & \multirow[t]{3}{*}{$N$} & \multirow{2}{*}{\multicolumn{2}{|c|}{$\frac{\text { Market index }}{\text { Market index }}$}} & \multicolumn{9}{|l|}{ Matched Firms } \\
\hline & & & & \multicolumn{2}{|l|}{ Size matched } & \multicolumn{4}{|c|}{ Size-and-book-to-market matched } & \multicolumn{3}{|c|}{$\begin{array}{l}\text { Industry-size-and-book-to-market } \\
\text { matched }\end{array}$} \\
\hline & & Mean CAR & $p$-Value & Mean CAR & $p$-Value & \multicolumn{2}{|c|}{ Mean CAR } & \multicolumn{2}{|c|}{$p$-Value } & Mean CAR & \multicolumn{2}{|c|}{$p$-Value } \\
\hline \multicolumn{13}{|c|}{ Panel A: equally weighted portfolios } \\
\hline All IPOs & 537 & $-74.83 \%$ & $0.000 * * *$ & $-17.78 \%$ & $0.005 * * *$ & \multicolumn{2}{|l|}{$-0.03 \%$} & \multicolumn{2}{|l|}{0.996} & $-6.09 \%$ & \multicolumn{2}{|c|}{0.437} \\
\hline Share-only IPOs & 400 & $-67.84 \%$ & $0.000 * * *$ & $-12.80 \%$ & $0.035 * *$ & \multicolumn{2}{|l|}{$9.68 \%$} & \multicolumn{2}{|c|}{0.237} & $1.67 \%$ & \multicolumn{2}{|c|}{0.846} \\
\hline Unit IPOs & 137 & $-95.22 \%$ & $0.000 * * *$ & $-32.33 \%$ & $0.006 * * *$ & \multicolumn{2}{|l|}{$-28.39 \%$} & \multicolumn{2}{|c|}{$0.050^{* *}$} & $-28.73 \%$ & \multicolumn{2}{|c|}{$0.039 * *$} \\
\hline \multicolumn{13}{|c|}{ Panel B: value-weighted portfolios } \\
\hline All IPOs & 537 & $-51.57 \%$ & $0.000 * * *$ & $-16.27 \%$ & 0.403 & $-24.89 \%$ & & 0.189 & & $22.11 \%$ & 0.2 & \\
\hline Share-only IPOs & 400 & $-48.32 \%$ & $0.000 * * *$ & $-15.21 \%$ & 0.467 & $-24.86 \%$ & & 0.223 & & $26.19 \%$ & 0.2 & \\
\hline \multirow[t]{3}{*}{ Unit IPOs } & 137 & $-90.47 \%$ & $0.000 * * *$ & $-28.92 \%$ & $0.017 * *$ & $-25.25 \%$ & & $0.053^{*}$ & & $-26.76 \%$ & 0.0 & $22 * *$ \\
\hline & \multirow[t]{2}{*}{$N$} & \multicolumn{2}{|l|}{ Market index } & \multicolumn{2}{|l|}{ Size matched } & \multicolumn{4}{|c|}{ Size-and-book-to-market matched } & \multicolumn{3}{|c|}{$\begin{array}{l}\text { Industry-size-and-book-to-market } \\
\text { matched }\end{array}$} \\
\hline & & Mean CAR & $p$-Value from $\mathrm{MW}^{\mathrm{a}}$ & Mean CAR & $p$-Value fr & om MW & Mea & CAR & $p$-Value from MW & Mean & AR & $p$-Value from MW \\
\hline $\begin{array}{l}\text { Panel C: unit IPOs v } \\
\text { Equally weighted }\end{array}$ & $\begin{array}{l}\text { ersus sl } \\
\text { portfol }\end{array}$ & $\begin{array}{l}\text { hare-only IPOs: } \\
\text { lios }\end{array}$ & 1990-1997 & & & & & & & & & \\
\hline Share-only IPOs & 238 & $-88.60 \% * * *$ & 0.226 & $-8.68 \%$ & $0.004 * * *$ & & & $39 \%$ & $0.001 * * *$ & -5.27 & & $0.017 * *$ \\
\hline Unit IPOs & 131 & $-97.37 \% * * *$ & & $-31.74 \% * * *$ & & & -33 . & $3 \% * * *$ & & 33.21 & $6 * * *$ & \\
\hline Value-weighted port & folios & & & & & & & & & & & \\
\hline Share-only IPOs & 238 & $-85.22 \% * * *$ & $0.000 * * *$ & $-10.84 \%$ & $0.000 * * *$ & & -4 & $28 \%$ & $0.000 * * *$ & -5.90 & & $0.014 * *$ \\
\hline Unit IPOs & 131 & $-92.43 \% * * *$ & & $-29.62 \% * *$ & & & -28 & $35 \% * *$ & & -30.18 & & \\
\hline
\end{tabular}

This table reports the 3-year post-IPO average cumulative abnormal return $(\overline{\mathrm{CAR}})$. The 3 -year $\overline{\mathrm{CAR}}$ is calculated as $\overline{\mathrm{CAR}}=\sum_{i=1}^{N} w_{i} \mathrm{CAR}_{i}$, where $w_{i}$ is the weight on firm $i$ and $N$ is the number of securities. The 3-year $\overline{\mathrm{CAR}}$ is calculated using both equally and value-weighted returns. The value weights are based on the market value of equity at the end of the event month. The stock $i$ 's event-induced cumulative abnormal return $\left(\mathrm{CAR}_{i}\right)$ is estimated as $\mathrm{CAR}_{i}=\sum_{t=1}^{36}\left(R_{i, t}-R_{\mathrm{B}, t}\right)$, where $R_{i, t}$ is the monthly return of IPO firm $i$ in month $t$ and $R_{\mathrm{B}, t}$ is the monthly return of benchmark firm or portfolio. We use various benchmarks, including value-weighted market index and a non-IPOs firm matched with the IPOs firm on size, size-and-book-to-market ratio, and industry-size-and-book-to-market ratio.

$* * *, * *$, and $*$ indicate significance at $1 \%, 5 \%$ and $10 \%$, respectively.

a MW refers to the non-parametric Mann-Whitney test. 
significantly worse than share-only IPOs in the long run. Thus, the evidence from the CARs runs contrary to the predictions of both agency cost and signaling models.

Table 5 reports the equally and value-weighted average BHARs generated by different IPOs samples and their benchmarks over the 3-year period. The equally weighted average BHARs suggest the long-term performance of IPOs samples depends largely on the choice of the reference portfolios. On average, the samples of all, share-only and unit IPOs significantly underperform the market index by $-61.64 \%,-55.02 \%$ and $-81.00 \%$, respectively. The observed negative long-term abnormal returns associated with these samples shrink to $-11.80 \%,-10.75 \%$ and $-14.84 \%$, respectively, when size matched firms are used as a benchmark. The underperformance disappears completely when the IPOs returns are compared with the returns of their size-and-bookto-market ratio or industry-size-and-book-to-market matched firms. Panel B of Table 5 shows that for the value-weighted average BHAR approach, the samples of all, share-only, and unit IPOs perform significantly worse than the market index by $-27.63 \%,-24.40 \%$ and $-66.32 \%$, respectively. However, when size and industry-size-and-book-to-market ratio matched firms are used as benchmarks, none of the three samples generates a statistically significant value-weighted average BHAR. The fact that value-weighted returns are generally higher than equally weighted returns suggest that the equally weighted mean BHAR is driven by small-firm stocks.

Panel C of Table 5 provides a direct comparison between the BHARs of share-only IPOs and unit IPOs over the period from 1990 to1997. Similar to the case of CARs, the non-parametric Mann-Whitney test suggests that share-only IPOs perform better than unit IPOs in the long run. These results are robust to different BHAR estimation methods. The finding that share-only IPOs outperform unit IPOs in the long run is not consistent with agency cost and signaling explanations of the unit issuance.

\subsection{Standard calendar-time regressions}

Fama (1998) argues that the event-time approach overstates the statistical inferences as it does not control for correlation among individual firms. To overcome these problems, we employ the following standard calendar-time regressions, which both test for the performance of a given portfolio beyond the level of which common risk factors can capture and automatically account for the cross-correlation of event firms in the portfolio variance ${ }^{14}$

$$
R_{\mathrm{p}, t}-R_{\mathrm{f}, t}=\alpha_{0}+\alpha_{1}\left(R_{\mathrm{m}, t}-R_{\mathrm{f}, t}\right)+\alpha_{2} \mathrm{SMB}_{t}+\alpha_{3} \mathrm{HML}_{t}+\alpha_{4} \mathrm{UMD}_{t}+\varepsilon_{t}
$$

where $R_{p, t}$ is the monthly return of the portfolio of event firms. At the beginning of each month, we form an equally and a value-weighted portfolio of firms that issue IPOs within the previous 3 years. ${ }^{15}$ The portfolios are rebalanced monthly to ensure that firms that reach the end of their 3year period are excluded and new issues are included. When $R_{\mathrm{p}, t}$ is computed on a value-weighted basis, the firm $i$ 's weight in forming the portfolios is its market value of equity at the end of the previous month. $R_{\mathrm{f}, t}$ is the monthly return of 1 -month Hong Kong Interbank Borrowing Rate. $R_{\mathrm{m}, t}$ is the monthly return on the value-weighted Hang Seng index. $\mathrm{SMB}_{t}$ (small minus big) and $\mathrm{HML}_{t}$ (high minus low) are the difference between the monthly returns of value-weighted portfolios of small minus big stocks and value-weighted portfolios of high and low book-to-market stocks,

\footnotetext{
14 Note that the inclusion of the liquidity factor of Eckbo and Norli (2005) in Eq. (5) does not alter our conclusions. Details are available upon request.

15 Again share-only IPOs and unit-IPOs are studied both separately and as a pooled group.
} 
Table 5

Three-year average cumulative abnormal return $(\overline{\mathrm{BHAR}})$ for the sample firms

\begin{tabular}{|c|c|c|c|c|c|c|c|c|c|c|c|c|c|}
\hline & \multirow[t]{3}{*}{$N$} & \multirow{2}{*}{\multicolumn{2}{|c|}{$\frac{\text { Market index }}{\text { Market index }}$}} & \multicolumn{10}{|l|}{ Matched Firms } \\
\hline & & & & \multicolumn{3}{|l|}{ Size matched } & \multicolumn{4}{|c|}{ Size-and-book-to-market matched } & \multicolumn{3}{|c|}{ Industry-size-and-book-to-market matched } \\
\hline & & Mean BHAR & $p$-Value & Mean BHAR & \multicolumn{2}{|c|}{$p$-Value } & \multicolumn{2}{|c|}{ Mean BHAR } & \multicolumn{2}{|c|}{$p$-Value } & \multicolumn{2}{|c|}{ Mean BHAR } & $p$-Value \\
\hline \multicolumn{14}{|c|}{ Panel A: equally weighted portfolios } \\
\hline All IPOs & 537 & $-61.64 \%$ & $0.000 * * *$ & $-11.80 \%$ & \multicolumn{2}{|c|}{0.113} & & $3 \%$ & \multicolumn{2}{|c|}{0.179} & \multicolumn{2}{|c|}{$-2.63 \%$} & 0.624 \\
\hline Share-only IPOs & 400 & $-55.02 \%$ & $0.000 * * *$ & $-10.75 \%$ & \multicolumn{2}{|c|}{$0.028 * *$} & & $7 \%$ & \multicolumn{2}{|c|}{$0.028 * *$} & \multicolumn{2}{|c|}{$0.43 \%$} & 0.921 \\
\hline Unit IPOs & 137 & $-81.00 \%$ & $0.000 * * *$ & $-14.84 \%$ & \multicolumn{2}{|c|}{$0.001 * * *$} & & $4 \%$ & \multicolumn{2}{|c|}{0.549} & \multicolumn{2}{|c|}{$-11.57 \%$} & 0.118 \\
\hline \multicolumn{14}{|c|}{ Panel B: value-weighted portfolios } \\
\hline All IPOs & 537 & $-27.63 \%$ & $0.003 * * *$ & $-7.14 \%$ & \multicolumn{2}{|c|}{0.262} & & $1 \%$ & \multicolumn{2}{|c|}{$0.100 *$} & \multicolumn{2}{|c|}{$4.38 \%$} & 0.277 \\
\hline Share-only IPOs & 400 & $-24.40 \%$ & $0.000 * * *$ & $-7.03 \%$ & \multicolumn{2}{|c|}{0.15} & -1 & $0 \%$ & \multicolumn{2}{|c|}{$0.027 * *$} & \multicolumn{2}{|c|}{$5.16 \%$} & 0.249 \\
\hline \multirow[t]{3}{*}{ Unit IPOs } & 137 & $-66.32 \%$ & $0.000 * * *$ & $-8.41 \%$ & \multicolumn{2}{|c|}{0.124} & & $8 \%$ & \multicolumn{2}{|c|}{0.465} & \multicolumn{2}{|c|}{$-5.00 \%$} & 0.438 \\
\hline & \multirow[t]{2}{*}{$N$} & \multicolumn{2}{|l|}{ Market index } & Size match & & & & Size-ar & d-book & to-market m & & $\begin{array}{l}\text { Industry-size- } \\
\text { matched }\end{array}$ & d-book-to-market \\
\hline & & Mean BHAR & $\begin{array}{l}p \text {-Value } \\
\text { from MW }\end{array}$ & Mean BHA & & $\begin{array}{l}p \text {-Val } \\
\text { from }\end{array}$ & & Mean I & HAR & $\begin{array}{l}p \text {-Value } \\
\text { from MW }\end{array}$ & & Mean BHAR & $\begin{array}{l}p \text {-Value } \\
\text { from MW }\end{array}$ \\
\hline $\begin{array}{l}\text { Panel C: unit IPOs } v \\
\text { Equally weighted }\end{array}$ & $\begin{array}{l}\text { ersus s } \\
\text { portfol }\end{array}$ & $\begin{array}{l}\text { are-only IPOs } 19 \\
\text { os }\end{array}$ & $90-1997$ & & & & & & & & & & \\
\hline Share-only IPOs & 238 & $-69.45 \% * * *$ & $0.001 * * *$ & $-3.40 \%$ & & 0.003 & & $7.88 \%$ & & $0.000 * * *$ & & $-4.11 \%$ & $0.076^{*}$ \\
\hline Unit IPOs & 131 & $-80.91 \% * * *$ & & $-13.09 \%$ & & & & $-8.90 \%$ & & & & $-12.66 \%$ ** & \\
\hline Value-weighted $\mathrm{p}$ & rtfolio & & & & & & & & & & & & \\
\hline Share-only IPOs & 238 & $-56.32 \% * * *$ & $0.000 * * *$ & $-7.77 \%$ & & 0.002 & & $-2.06 \%$ & & $0.000 * * *$ & & $-4.453 \%$ & $0.029 * *$ \\
\hline Unit IPOs & 131 & $-66.433 \% * * *$ & & $-7.84 \%$ & & & & $-0.01 \%$ & & & & $-5.881 \%$ & \\
\hline
\end{tabular}

This table reports the 3-year post-IPO average buy and hold return $(\overline{\mathrm{BHAR}})$. The 3 -year $\overline{\mathrm{BHAR}}$ is calculated as $\overline{\mathrm{BHAR}}=\sum_{i=1}^{N} w_{i} \mathrm{BHAR}_{i}$, where $w_{i}$ is the weight on firm $i$ and $N$ is the number of securities. The 3 -year $\overline{\mathrm{BHAR}}$ is calculated using both equally and value-weighted returns. The value weights are based on the market value of equity at the end of the event month. The stock $i$ 's event-induced cumulative abnormal return $\left(\mathrm{BHAR}_{i}\right)$ is estimated as $\mathrm{BHAR}_{i}=\prod_{t=1}^{36}\left(1+R_{i, t}\right)-\prod_{t=1}^{36}\left(1+R_{\mathrm{B}, t}\right)$, where $R_{i, t}$ is the monthly return of IPOs firm $i$ in month $t$ and $R_{\mathrm{B}, t}$ is the monthly return of benchmark firm or portfolio. We use various benchmarks, including value-weighted market index and a non-IPOs firm matched with the IPOs firm on size, size-and-book-to-market ratio, and industry-size-and-book-to-market ratio.

$* *, * *$, and $*$ indicate significance at $1 \%, 5 \%$ and $10 \%$, respectively.

${ }^{a} \mathrm{MV}$ refers to the non-parametric Mann-Whitney test. 
respectively. $\mathrm{SMB}_{t}$ and $\mathrm{HML}_{t}$ are constructed using the same algorithm as Fama and French (1993). $\mathrm{UMD}_{t}$ is a momentum factor constructed in the same way as Eckbo and Norli (2005). The intercept, $\alpha_{0}$, measures the average monthly abnormal return of the portfolio of event firms.

The results from the weighted least square (WLS) estimation of standard calendar-time regressions are reported in Table $6 .{ }^{16}$ Panel A of Table 6 shows that under the standard calendar-time regression, the equally weighted portfolios of all, share-only and unit IPOs generate statistically significant mean abnormal returns of $-1.2 \%(-43.2 \%),-1.1 \%(-39.6 \%)$ and $-1.2 \%(-43.2 \%)$ per month (for a 3-year period), respectively. The intercept of unit IPOs is greater than the intercept of share-only IPOs in absolute value. However, the evidence reported in panel B of Table 6 suggests that the intercept of the standard calendar-time regression is not statistically significant when value-weighted portfolios are used in the estimation.

The disappearance of long-term IPOs underperformance when value-weighted portfolios are used has two possible explanations. First, the negative abnormal returns are more pronounced for small-firms and value-weighted portfolio returns are biased towards big firms (see, for example, Loughran and Ritter, 2000). Second, since our samples are tilted towards small and high growth firms, the standard calendar-time factor regression is likely to overreject the null hypothesis of zero intercept (see, Fama, 1998; Mitchell and Stafford, 2000). To avoid the overrejection problem associated with the standard calendar-time factor regression, we use matched calendar-time factor regression in the next section.

\subsection{Matched calendar-time regressions}

One problem with standard calendar-time regressions is linked to the possibility of overrejecting the null hypothesis of zero intercept in the case of small and high growth stocks. Since the IPOs firms are generally small and high growth firms, the problem of overrejecting the null hypothesis is particularly severe. To avoid these problems, Boehme and Sorescu (2002), Boehme and Danielson (in press) and Cheng (2005) recommend the use of a zero-investment calendar-time portfolio consisting of long positions on event firms and short positions on the matched non-event firms. The zero-investment calendar-time portfolio approach used in this study can be described as follows ${ }^{17}$

$$
R_{\mathrm{p}, t}-R_{\mathrm{c}, t}=\beta_{0}+\beta_{1}\left(R_{\mathrm{m}, t}-R_{\mathrm{f}, t}\right)+\beta_{2} \mathrm{SMB}_{t}+\beta_{3} \mathrm{HML}_{t}+\beta_{4} \mathrm{UMD}_{t}+\xi_{t}
$$

where $R_{\mathrm{c}, t}$ is the monthly return of the matched portfolio of non-event stocks constructed on both an equally weighted and a value-weighted basis. The non-event stocks are matched to the event stocks based on size, size-and-book-to-market, and industry-size-and-book-to-market as shown in Section 2.2. The intercept $\beta_{0}$ in Eq. (6) is the average monthly abnormal return of the portfolio that specifically corrects for (i) size, (ii) size-and-book-to-market ratio, and (iii) industry, sizeand-book-to-market ratio. If small and low book-to-market ratio stocks are not well described by the standard factor model in Eq. (5), the zero-investment calendar-time approach should correct

\footnotetext{
16 Since only six unit IPOs are issued between 1998 and 2002 (see Table 1), few monthly observations are available in the later years. The weighted least square (WLS) is used to control for the differences in the number of IPO observations across different calendar months. The weight used is the square root of the number of IPOs observations. Note we also estimate the standard calendar-time regression over 1990-1997 period and our conclusions remain unchanged (the results are available upon request).

17 Similar to the case of standard calendar-time regression, including the liquidity factor of Eckbo and Norli (2005) does not cause any noticeable changes to our results. Further details are available upon request.
} 
Table 6

The post-issue 3-year abnormal returns from the standard calendar-time factor regression

\begin{tabular}{|c|c|c|c|c|c|c|c|c|c|c|c|}
\hline & $\alpha_{0}^{1}$ & $p$-Value & $\alpha_{1}$ & $p$-Value & $\alpha_{2}$ & $p$-Value & $\alpha_{3}$ & $p$-Value & $\alpha_{4}$ & $p$-Value & $R$-square \\
\hline \multicolumn{12}{|c|}{ Panel A: equally weighted portfolios } \\
\hline All IPOs & $-0.012 * * *$ & 0.000 & $0.962 * * *$ & 0.000 & $0.962 * * *$ & 0.000 & $0.403 * * *$ & 0.000 & -0.060 & 0.314 & 0.901 \\
\hline Share-only IPOs & $-0.011 * * *$ & 0.002 & $0.961 * * *$ & 0.000 & $0.941 * * *$ & 0.000 & $0.397 * * *$ & 0.000 & -0.069 & 0.242 & 0.895 \\
\hline Unit IPOs & $-0.012 * * *$ & 0.006 & $0.995^{* * *}$ & 0.000 & $1.094 * * *$ & 0.000 & $0.343 * * *$ & 0.023 & -0.004 & 0.979 & 0.724 \\
\hline \multicolumn{12}{|c|}{ Panel B: value-weighted portfolios } \\
\hline All IPOs & 0.002 & 0.560 & $0.961 * * *$ & 0.000 & $0.442 * * *$ & 0.000 & $0.142 * * *$ & 0.131 & $-0.165 * *$ & 0.020 & 0.817 \\
\hline Share-only IPOs & 0.002 & 0.661 & $0.964 * * *$ & 0.000 & $0.409 * * *$ & 0.000 & $0.155^{* * *}$ & 0.115 & $-0.169 * *$ & 0.022 & 0.808 \\
\hline Unit IPOs & 0.008 & 0.168 & $0.998 * * *$ & 0.000 & $0.936 * * *$ & 0.000 & $0.178 * * *$ & 0.210 & 0.113 & 0.406 & 0.643 \\
\hline
\end{tabular}

This table reports the post-issue 3-year abnormal returns associated with AIPOs, SIPOs and UIPOs using the weighted least square (WLS ${ }^{2}$ ) estimation of the following standard calendar-time factor regression: $R_{\mathrm{p}, t}-R_{\mathrm{f}, t}=\alpha_{0}+\alpha_{1}\left(R_{\mathrm{m}, t}-R_{\mathrm{f}, t}\right)+\alpha_{2} \mathrm{SMB}_{t}+\alpha_{3} \mathrm{HML}_{t}+\alpha_{4} \mathrm{UMD}_{t}+\varepsilon_{t}$, where $R_{\mathrm{p}, t}$ is the monthly return of the portfolio of event firms. In each month, we form equally and value-weighted portfolio of AIPOs, SIPOs and UIPOs within the previous 3 years. The portfolios are rebalanced monthly to ensure that the firms that reach the end of their 3-year period are excluded and the new issues are included. When $R_{\mathrm{p}, t}$ is computed on value-weighted basis, the firm $i$ 's weight in forming the portfolios is its market of equity at the end of the previous month. $R_{\mathrm{f}, t}$ is the monthly return of 1-month Hong Kong Interbank Borrowing Rate (HKIBOR). $R_{\mathrm{m}, t}$ is the monthly return on the value-weighted HKSE index. $\mathrm{SMB}_{t}$ (small minus big) and $\mathrm{HML}_{t}$ (high minus low) are the difference between the monthly returns of value-weighted portfolios of small minus big stocks and value-weighted portfolios of high and low book-to-market stocks, respectively. $\mathrm{SMB}_{t}$ and $\mathrm{HML}_{t}$ are constructed using the same algorithm as Fama and French (1993). $\mathrm{UMD}_{t}$ is a momentum factor generated using the same methodology as Eckbo and Norli (2005). The intercept, $\alpha_{0}$, measures the average monthly abnormal return of the portfolio of event firms.

${ }^{1}$ The statistical significance is generated after conducting for White heteroskedasticity adjustments. ${ }^{2}$ The weight used is the square root of the number of IPO observations. $* * *$, $* *$, and $*$ indicate significance at $1 \%, 5 \%$ and $10 \%$, respectively. 
for the biases in the intercept. The rest of the variables are defined in the same way as in Section 3.2 .

Table 7 reports the results from the WLS estimation of the matched calendar-time four-factor regressions. In panel A of Table 7, we employ the matched calendar-time regression to analyse the equally weighted portfolio returns. The samples of all, share-only and unit IPOs underperform their size matched firms by $-0.50 \%,-0.30 \%$ and $-0.80 \%$ per month, respectively. However, the observed negative abnormal returns are not significantly different from zero. The abnormal returns associated with the three samples are also not significant when size-and-book-to-market ratio or industry-size-and-book-to-market ratio matched firms are used as benchmarks. In panel B of Table 7, we report the results from WLS estimation of the matched calendar-time fourfactor regressions using value-weighted portfolio returns. Similar to the case of equally weighted portfolio returns, the abnormal returns associated with the three IPOs samples are not significantly different from zero. These findings hold regardless of whether size, size-and-book-to-market ratio, or industry-size-and-book-to-market ratio matched firms are used as benchmarks.

For a more direct comparison between the performance of share-only and unit IPOs, we reestimate Eq. (6) using $R_{\mathrm{p}, t}$ as the monthly returns of the portfolio of share-only IPOs and $R_{\mathrm{c}, t}$ as the monthly returns of the portfolio of unit IPOs. Due to the fact that only six unit IPOs are issued during 1998-2002 period (see Table 1), we re-estimate Eq. (6) only for the period from 1990 to 1997. Table 7 shows that, regardless of whether equally or value-weighted portfolios are used, the intercept of Eq. (6), when $R_{\mathrm{p}, t}$ is defined as the monthly returns of the portfolio of share-only IPOs and $R_{\mathrm{c}, t}$ as the monthly returns of the portfolio of unit IPOs, is not statistically significant from zero.

Overall, the event-time average CARs and BHARs suggest that unit IPOs significantly underperform share-only IPOs in the long run. Even if the event-time approach may not appropriately account for the riskiness of unit and share-only IPOs, this evidence remains inconsistent with the signaling model, which expects unit IPOs to be riskier and, therefore, generate higher long-term returns than share-only IPOs at least before conducting appropriate risk adjustments. Given the potential problems associated with the use of the event-time approach, we employ the matched calendar-time regression methodology. Under the matched calendar-time regression approach, we find no evidence that unit IPOs outperform share-only IPOs in the long run. This finding runs against the predictions of the agency cost model, which expects unit IPOs to possess better quality of investments, and hence generate higher long-term risk-adjusted returns than share-only IPOs.

\subsection{Robustness checks}

This sub-section examines whether the long-term performance of share-only and unit IPOs depends on type of shares issued or the characteristics of warrants included as part of the unit IPOs packages. ${ }^{18}$

\subsubsection{Chinese versus non-Chinese IPOs}

Table 8 summarizes the size and the book-to-market ratio characteristics of Chinese and nonChinese IPOs listed on the HKSE. ${ }^{19}$ The table shows that Chinese IPOs are significantly bigger

\footnotetext{
18 We are grateful to the anonymous referee for suggesting this approach.

19 Our sample contains 76 Chinese IPOs, which may differ in their characteristics from non-Chinese IPOs firms issued in Hong Kong. Chinese IPOs include H shares and red chip companies. H shares are incorporated in the mainland China
} 
Table 7

The post-issue 3-year abnormal return from the matched calendar-time factor regression

\begin{tabular}{|c|c|c|c|c|c|c|c|c|c|c|c|c|}
\hline & \multicolumn{3}{|c|}{ Size match } & \multicolumn{3}{|c|}{ Size-and-book-to-market match } & \multicolumn{3}{|c|}{$\begin{array}{l}\text { Industry-size-and-book-to-market } \\
\text { match }\end{array}$} & \multicolumn{3}{|c|}{$\begin{array}{l}\text { Share-only versus unit IPOs } \\
(1990-1997)^{2}\end{array}$} \\
\hline & $\beta_{0}^{1}$ & $p$-Value & $R$-square & $\beta_{0}$ & $p$-Value & $R$-square & $\beta_{0}$ & $p$-Value & $R$-square & $\beta_{0}$ & $p$-Value & $R$-square \\
\hline \multicolumn{13}{|c|}{ Panel A: equally weighted portfolios } \\
\hline All IPOs & -0.005 & 0.108 & 0.048 & -0.002 & 0.527 & 0.038 & -0.002 & 0.492 & 0.025 & & & \\
\hline Share-only IPOs & -0.003 & 0.301 & 0.073 & -0.001 & 0.741 & 0.054 & -0.001 & 0.772 & 0.033 & 0.004 & 0.508 & 0.067 \\
\hline Unit IPOs & -0.008 & 0.140 & 0.016 & 0.001 & 0.834 & 0.036 & -0.005 & 0.423 & 0.011 & & & \\
\hline \multicolumn{13}{|c|}{ Panel B: value-weighted portfolios } \\
\hline All IPOs & 0.001 & 0.836 & 0.039 & -0.001 & 0.859 & 0.034 & 0.004 & 0.302 & 0.039 & \multirow{3}{*}{\multicolumn{2}{|c|}{$-0.0060 .345$}} & \\
\hline Share-only IPOs & 0.001 & 0.862 & 0.042 & -0.001 & 0.770 & 0.042 & 0.005 & 0.221 & 0.050 & & & 0.270 \\
\hline Unit IPOs & 0.000 & 0.989 & 0.024 & 0.011 & 0.164 & 0.023 & -0.005 & 0.614 & 0.023 & & & \\
\hline
\end{tabular}

This table reports the post-issue 3-year abnormal returns associated with AIPOs, SIPOs and UIPOs using the weighted least square (WLS) estimation of the following matched calendar-time factor regression: $R_{\mathrm{p}, t}-R_{\mathrm{c}, t}=\beta_{0}+\beta_{1}\left(R_{\mathrm{m}, t}-R_{\mathrm{f}, t}\right)+\beta_{2} \mathrm{SMB}_{t}+\beta_{3} \mathrm{HML}_{t}+\beta_{4} \mathrm{UMD}_{t}+\xi_{\mathrm{t}}$, where $R_{c, \mathrm{t}}$ is the monthly return of the matched portfolio of non-IPOs stocks constructed on both an equally weighted and a value-weighted basis. The non-IPOs stocks are matched to the IPOs stocks based on size, size-and-book-to-market, and industry-size-and-book-to-market as shown in Section 2.2. The rest of the variables are defined in the notes of Table 6 . The intercept $\beta_{0}$ is the average monthly abnormal return of the portfolio that specifically corrects for size, size-and-book-to-market ratio, and industry-size-and-book-to-market ratio. If small and low book-to-market ratio stocks are not well described by the standard factor model, the zero-investment calendar-time factor regression should correct for the biases in the intercept.

${ }^{1}$ The statistical significance is generated after conducting White heteroskedasticity adjustment. ${ }^{2}$ To compare the performance of share-only and unit IPOs directly, we re-estimate Eq. (6) using $R_{\mathrm{p}, t}$ as the monthly return of the portfolio of share-only IPOs and $R_{\mathrm{c}, t}$ is the monthly returns of the portfolio of unit IPOs firms. ${ }^{3}$ The weight used is the square root of the number of IPOs observations. 
Table 8

The characteristics of Chinese and non-Chinese IPOs

\begin{tabular}{lccc}
\hline & Chinese $(N=76)$ & Non-Chinese $(N=461)$ & $p$-Value from MW \\
\hline & & & PanelA: allIPOs \\
Size & 7473.35 & 1205.57 & $0.000^{* * * *}$ \\
Book-to-market ratio & 0.99 & 0.69 & $0.000^{* * *}$
\end{tabular}

\begin{tabular}{lccl} 
& Chinese $(N=68)$ & Non-Chinese $(N=332)$ & $p$-value from MW \\
\hline Panel B: share-only IPOs & & & \\
$\quad$ Size & 8045.33 & 1476.52 & $0.000^{* * *}$ \\
Book-to-market ratio & 1.05 & 0.67 & $0.000^{* * *}$ \\
& Chinese $(N=8)$ & Non-Chinese $(N=129)$ & $p$-value from MW \\
& & & \\
Panel C: unit IPOs & 2611.53 & 508.24 & $0.000^{* * *}$ \\
Size & 0.51 & 0.75 & 0.644 \\
Book-to-market ratio & &
\end{tabular}

This table describes the size-and-book-to-market characteristics of Chinese and non-Chinese IPOs firms listed on the HKSE between 1990 and 2002. Size is the market value of equity, which is calculated as the number of shares outstanding multiplied by the share price at the beginning of the month. For each month, book-to-market ratio is computed as the book values from the most recent fiscal year after the IPOs divided by the market value of equity.

** Indicates significance at $1 \%$ level.

${ }^{\text {a }}$ MW is non-parametric Mann-Whitney test.

in size than non-Chinese IPOs. The average book-to-market ratio associated with Chinese shareonly IPOs is significantly higher than that of non-Chinese share-only IPOs. However, Chinese unit IPOs are not significantly different from non-Chinese unit IPOs in terms of their average bookto-market ratio. Given the obvious differences between Chinese and non-Chinese IPOs listed in Hong Kong, it is important to check whether our reported results are affected by the inclusion of Chinese IPOs in the analysis.

Table 9 reports the results from the matched calendar-time regression (Eq. (6)) applied to Chinese and non-Chinese IPOs firms separately. The average monthly abnormal returns $\left(\beta_{0}\right.$ in Eq. (6)) associated with Chinese and non-Chinese all, share-only, and unit IPOs samples are not significantly different from zero. These findings are robust regardless of whether the size, size-and-book-to-market ratio, or industry-size-and-book-to-market ratio is used as a matching procedure. The results are also robust to the use of equally and value-weighted portfolios of event and non-event firms. ${ }^{20}$

\subsubsection{Warrant characteristics}

Garner and Marshall (2005) show that firms with different risk profiles may choose to issue different types of warrants. Specifically, risky (less risky) firms tend to issue warrants with longer

and approved by the China Securities Regulatory Commission to be listed on the HKSE. Rep chip is mainland controlled companies incorporated outside mainland China and listed on the HKSE. If IPOs characteristics play an important role in determining the long-term performance of the issuing firms, Chinese and non-Chinese IPOs may generate different abnormal returns.

${ }^{20}$ We also applied the event-time and the standard calendar-time approach separately to Chinese and non-Chinese all, share-only, unit IPOs samples. The overall results are in line to those reported in Sections 3.1 and 3.2. Details are available upon request. 
Table 9

The post-issue 3-year abnormal returns from the matched calendar-time regression for Chinese and non-Chinese IPO firms

\begin{tabular}{|c|c|c|c|c|c|c|c|c|c|}
\hline & \multicolumn{3}{|c|}{ Size match } & \multicolumn{3}{|c|}{ Size-and-book-to-market match } & \multicolumn{3}{|c|}{ Industry-size-and-book-to-market match } \\
\hline & $\beta_{0}$ & $p$-Value & $R$-square & $\beta_{0}$ & $p$-Value & $R$-square & $\beta_{0}$ & $p$-Value & $R$-square \\
\hline \multicolumn{10}{|l|}{ Panel A: Chinese IPOs } \\
\hline \multicolumn{10}{|c|}{ Equally weighted portfolios } \\
\hline All IPOs & 0.006 & 0.629 & 0.139 & 0.006 & 0.628 & 0.209 & 0.000 & 0.974 & 0.148 \\
\hline Share-only IPOs & 0.008 & 0.505 & 0.134 & 0.010 & 0.453 & 0.211 & 0.004 & 0.768 & 0.153 \\
\hline Unit IPOs & 0.001 & 0.961 & 0.039 & 0.015 & 0.422 & 0.084 & 0.002 & 0.888 & 0.051 \\
\hline \multicolumn{10}{|c|}{ Value-weighted portfolios } \\
\hline All IPOs & -0.006 & 0.616 & 0.111 & -0.011 & 0.332 & 0.155 & -0.004 & 0.711 & 0.132 \\
\hline Share-only IPOs & -0.002 & 0.899 & 0.123 & -0.008 & 0.566 & 0.127 & 0.000 & 0.976 & 0.101 \\
\hline Unit IPOs & -0.012 & 0.360 & 0.056 & 0.006 & 0.716 & 0.040 & -0.015 & 0.287 & 0.118 \\
\hline \multicolumn{10}{|c|}{ Panel B: non-Chinese IPOs } \\
\hline \multicolumn{10}{|c|}{ Equally weighted portfolios } \\
\hline All IPOs & -0.006 & 0.209 & 0.065 & -0.005 & 0.226 & 0.139 & -0.008 & 0.163 & 0.131 \\
\hline Share-only IPOs & -0.005 & 0.301 & 0.149 & -0.004 & 0.371 & 0.204 & -0.005 & 0.293 & 0.213 \\
\hline Unit IPOs & -0.006 & 0.458 & 0.048 & -0.004 & 0.511 & 0.135 & -0.019 & 0.190 & 0.049 \\
\hline \multicolumn{10}{|c|}{ Value-weighted portfolios } \\
\hline All IPOs & 0.001 & 0.927 & 0.270 & -0.004 & 0.409 & 0.087 & -0.007 & 0.222 & 0.263 \\
\hline Share-only IPOs & 0.001 & 0.864 & 0.283 & -0.005 & 0.371 & 0.102 & -0.008 & 0.154 & 0.276 \\
\hline Unit IPOs & 0.016 & 0.248 & 0.029 & 0.013 & 0.338 & 0.089 & 0.005 & 0.644 & 0.055 \\
\hline
\end{tabular}

This table reports the post-issue 3-year abnormal returns associated with Chinese and non-Chinese all, share-only, and unit IPOs samples using the weighted least square (WLS) estimation of the matched calendar-time factor regression. Details on the matched calendar-time approach are reported in notes of Table 7. 
Table 10

Warrant characteristics and the long-term performance of unit IPO firms

\begin{tabular}{|c|c|c|c|c|c|c|c|c|c|}
\hline & $\beta_{0}$ & $p$-Value & $R$-square & $\beta_{0}$ & $p$-Value & $R$-square & $\beta_{0}$ & $p$-Value & $R$-square \\
\hline \multicolumn{10}{|c|}{ Panel A: maturity } \\
\hline \multicolumn{10}{|c|}{ Equally weighted portfolios } \\
\hline$<$ median (Short) & -0.008 & 0.327 & 0.035 & -0.007 & 0.386 & 0.015 & -0.016 & 0.101 & 0.022 \\
\hline$\geq \operatorname{median}$ (Long) & -0.005 & 0.438 & 0.014 & 0.003 & 0.683 & 0.063 & -0.005 & 0.441 & 0.008 \\
\hline \multicolumn{10}{|c|}{ Value-weighted portfolios } \\
\hline <median (Short) & -0.007 & 0.573 & 0.004 & -0.003 & 0.808 & 0.010 & -0.016 & 0.207 & 0.056 \\
\hline$\geq$ median (Long) & 0.005 & 0.576 & 0.021 & $0.015^{*}$ & 0.066 & 0.087 & -0.004 & 0.728 & 0.028 \\
\hline \multicolumn{10}{|c|}{ Panel B: exercise price to offer price } \\
\hline \multicolumn{10}{|c|}{ Equally weighted portfolios } \\
\hline <median (Low) & -0.001 & 0.926 & 0.033 & 0.005 & 0.533 & 0.043 & 0.002 & 0.840 & 0.004 \\
\hline$\geq$ median (High) & -0.003 & 0.759 & 0.018 & 0.008 & 0.354 & 0.055 & -0.015 & 0.280 & 0.074 \\
\hline \multicolumn{10}{|c|}{ Value-weighted portfolios } \\
\hline <median (Low) & 0.000 & 0.974 & 0.015 & 0.007 & 0.566 & 0.031 & -0.001 & 0.961 & 0.004 \\
\hline$\geq \operatorname{median}($ High $)$ & 0.010 & 0.441 & 0.014 & $0.020^{*}$ & 0.060 & 0.045 & -0.004 & 0.814 & 0.052 \\
\hline
\end{tabular}

This table reports the results of testing whether the characteristics of the unit IPOs warrants affect the long-term performance of the issuing firms. We segregate our unit IPOs sample by warrant maturity and exercise price to offer price. We classify unit IPOs with maturity shorter than median as Short while the remaining firms are referred to as Long. We also refer to the unit IPOs with exercise price to offer price lower than median as low and the remaining firms are classified as high. The table reports the post-issue 3-year abnormal returns using the weighted least square (WLS) estimation of the matched calendar-time factor regression. More details on this regression can be found in the notes of Table 7 .

${ }^{*}$ Indicates significance at $10 \%$ level. 
(shorter) maturity and lower (higher) exercise price to offer price. If the characteristics of warrants in the unit IPOs packages reflect the issuers' riskiness, the long-term price performance of unit IPOs may be affected by warrant's maturity and its exercise price to offer price. To test this hypothesis, we segregate our unit IPOs sample by warrant maturity and exercise price to offer price. We classify unit IPOs with maturity shorter than median as Short while the remaining firms are referred to as Long. We also refer to the unit IPOs with exercise price to offer price lower than median as Low and the remaining firms are classified as High.

Table 10 presents the results from the matched calendar approach applied to the sub-samples of Short, Long, High, and Low. ${ }^{21}$ The table shows that Long and High generate significantly higher abnormal returns than their control stocks only when size-and-book-to-market ratio matching jointly with value-weighted portfolios are used in the matched calendar-time regression. In the rest of the cases, the average monthly abnormal returns $\left(\beta_{0}\right.$ in Eq. (6)) associated with Short, Long, High and Low are not significantly different from zero indicating that the performance of unit IPOs does not depend on the type of warrants issued.

\section{Conclusion}

Most of the previous studies show that IPOs exhibit significantly negative abnormal returns over holding periods of 2-5 years subsequent to the issue date. This long-term abnormal return anomaly contradicts even the weakest form of the efficient market hypothesis. Additionally, Byoun (2004) documents that unit SEOs underperform both share-only SEOs and various benchmarks of matched firms. These findings are not consistent with the recent theories explaining the role of unit financing in reducing agency costs or signaling.

The event-time abnormal return measures suggest that both share-only and unit IPOs significantly underperform the market index and that unit IPOs generate significantly lower abnormal returns than share-only IPOs. Even if the event-time approach may not adequately account for the risk, this evidence still runs against the predictions of the signaling model. Specifically, the signaling model suggests that unit IPOs are relatively riskier and should, therefore, yield higher returns than share-only IPOs in the long run at least before adjusting for risk.

When matched calendar-time regression approach is used, we show no evidence that unit IPOs generate significantly higher risk-adjusted returns than share-only IPOs in the long run. These findings run contrary to the predictions of the agency cost model, which expects unit IPOs to possess better quality projects and, therefore, yield higher long-term risk-adjusted returns than share-only IPOs. In general, our results do not support the predictions of either model.

\section{References}

Aggarwal, R.K., Punanandam, A.K., Wu, G., 2006. Underwriter manipulation in initial public offerings, Working paper, University of Minnesota.

Álvarez, S., González, V.M., 2005. Signaling and the long-run performance of Spanish initial public offerings (IPOs). Journal of Business Finance and Accounting 32, 325-350.

Barber, B., Lyon, J., 1997. Detecting long-run abnormal stock returns: the empirical power and specification of test statistics. Journal of Financial Economics 43, 341-372.

Boehme, R.D., Sorescu, S.M., 2002. The long-run performance following dividend initiations and resumptions: underreaction or product of chance? Journal of Finance 57, 871-900.

\footnotetext{
21 Again, we conduct the sub-sample analysis using the event-time and the standard calendar-time and the conclusions reported in Sections 3.1 and 3.2 remain unchanged. More details can be obtained from the authors.
} 
Boehme, R.D., Danielson, B.R., in press. Stock split post-announcement returns: underreaction or market friction? The Financial Review.

Brown, S.J., Warner, J.B., 1980. Measuring security price performance. Journal of Financial Economics 8, $205-258$.

Byoun, S., 2004. Stock performance following seasoned stock-warrant unit offerings. Journal of Business 77, 75-100.

Chan, Y., Wei, K.C.J., 2001. Price and volume effects associated with derivative warrants issuance on the Stock Exchange of Hong Kong. Journal of Banking and Finance 25, 1401-1426.

Chemmanur, T.J., Fulghieri, P., 1997. Why include warrants in new equity issues? A theory of unit IPOs. Journal of Financial and Quantitative Analysis 32, 1-24.

Cheng, Y., 2005. Post-listing underperformance: is it really bad to move trading locations? Journal of Corporate Finance 12, 97-120.

Eckbo, B.E., Norli, ø., 2005. Liquidity risk, leverage and long-run IPO returns. Journal of Corporate Finance 11, 1-35.

Fama, E.F., 1998. Market efficiency, long-term returns, and behavioural finance. Journal of Financial Economics 49, 283-306.

Fama, E.F., French, K., 1993. Common risk factors in returns on stocks and bonds. Journal of Financial Economics 33 , 3-56.

Garner, J.L., Marshall, B.B., 2005. Unit IPOs: what the warrant characteristics reveal about the issuing firm. Journal of Business 78 (5), 1837-1858.

How, J.C.Y., Howe, J.S., 2001. Warrants in initial public offerings: empirical evidence. Journal of Business 74, 433-458.

Lee, M., Lee, P., Taylor, S., 2003. Unit initial public offerings: staged equity or signaling mechanisms? Accounting and Finance 43, 63-85.

Loughran, T., Ritter, J.R., 1995. The new issues puzzle. Journal of Finance 50, 23-51.

Loughran, T., Ritter, J.R., 2000. Uniformly least powerful tests of market efficiency. Journal of Financial Economics 55, 361-389.

Lyon, J.D., Barber, B.M., Tsai, C.L., 1999. Improved methods for tests of long-run abnormal stock returns. Journal of Finance 54, 165-201.

Mitchell, M., Stafford, E., 2000. Managerial decisions and long-term stock price performance. Journal of Business 73 , 287-329.

Ritter, J.R., 1991. The long-run performance of initial public offerings. Journal of Finance 46, 3-27.

Schultz, P., 1993. Unit initial public offerings: a form of staged financing. Journal of Financial Economics 34, 199-229. 